\title{
Reproducibility and validity of portable haemoglobinometer for the diagnosis of anaemia in children under the age of 5 years
}

\author{
Alessandra da Silva Pereira ${ }^{1}$, Inês Rugani Ribeiro de Castro $^{2}$, Flávia Fioruci Bezerra ${ }^{3}$, \\ José Firmino Nogueira Neto ${ }^{4}$ and Ana Carolina Feldenheimer da Silva ${ }^{2}$ \\ ${ }^{1}$ Departamento de Nutrição Fundamental, Universidade Federal do Estado do Rio de Janeiro, Rio de Janeiro, Braz̦il \\ ${ }^{2}$ Departamento de Nutrição Social, Universidade do Estado do Rio de Janeiro, Rio de Janeiro, Brazil \\ ${ }^{3}$ Departamento de Nutrição Básica e Experimental, Universidade do Estado do Rio de Janeiro, Rio de Janeiro, Brazil \\ ${ }^{4}$ Laboratório de Lipídeos/Policlinica Piquet Carneiro/UERJ, Rio de Janeiro, Brazil
}

Received 5 September 2019 - Final revision received 4 December 2019 - Accepted 10 December 2019)

Journal of Nutritional Science (2020), vol. 9, e3, page 1 of 9

doi:10.1017/jns.2019.43

Abstract

Portable haemoglobinometers have been used in order to estimate the prevalence of anaemia in diverse settings. However, few studies have been conducted to evaluate their performance in children of different age groups in distinct epidemiological contexts. To evaluate the reproducibility and reliability of a portable haemoglobinometer for the diagnosis of anaemia in children $<5$ years $\mathrm{Hb}$ was measured in the venous blood of 351 children $<5$ years by an automated system (standard method) and in three capillary blood samples, using a portable haemoglobinometer (HemoCue ${ }^{\circledR}$; test method). The reproducibility of the device and of the test method was evaluated using the intraclass correlation coefficient (ICC) (Hb in its continuous form), $\kappa$ and prevalenceadjusted bias-adjusted $\kappa$ (PABAK) (categorised variable: anaemia: yes/no). For test method validation, Bland-Altman analyses were performed and sensitivity, specificity, accuracy rate, positive predictive value (PPV) and negative predictive values (NPV) were calculated. The haemoglobinometer presented good device reproducibility $(\mathrm{ICC}=0.79)$ and reasonable method reproducibility (puncture, collection and reading) $($ ICC $=0.71)$. Superficial and fair agreement $(\kappa)$ and good agreement (PABAK) were observed among the diagnoses obtained through the test method. The prevalence of anaemia was 19.1 and $19.7 \%$ using the standard and the test method, respectively, with no statistically significant differences. The test method presented higher specificity $(87.7 \%)$ and NPV $(88.3 \%)$ than sensitivity $(50.7 \%)$ and PPV (49.3\%), and intermediary accuracy rate $(57 \cdot 8 \%)$. HemoCue ${ }^{\circledR}$ showed good device reproducibility and reasonable method reproducibility, as well as good performance in estimating the prevalence of anaemia. Nevertheless, it showed a fair reliability and low individual diagnostic accuracy.

Key words: Children: Anaemia: Reproducibility: Accuracy

Fe-deficiency anaemia, the final stage of Fe deficiency, is a condition which can make an impact on children's health and development ${ }^{(1-3)}$. High Fe-deficiency anaemia prevalence has had an impact on both health and the economy in countries around the world; therefore much effort has been put into the prevention and treatment of this blood disorder in the last few decades ${ }^{(3)}$.

Anaemia can result from many conditions, including acute/ chronic inflammation, infectious diseases and haematological disorders, as well as insufficient intake of folate, vitamin $B_{12}$ or, most commonly, $\mathrm{Fe}^{(2,3)}$. In this way, it is vital to appropriately estimate the prevalence of Fe-deficiency anaemia to inform the planning and evaluation of public policies. Thus, it is essential that an appropriate diagnostic method be adopted, since its performance can influence the ability to estimate the prevalence of this condition.

Usually, anaemia diagnosis is based on the blood concentration of $\mathrm{Hb}$ (referred to as ' $\mathrm{Hb}$ '), which can be analysed by different methods ${ }^{(4-6)}$. The standard method is the analysis of

* Corresponding author: Alessandra da Silva Pereira, email aspnutri@gmail.com

Abbreviations: ICC, intraclass correlation coefficient; NPV, negative predictive value; PABAK, prevalence-adjusted bias-adjusted $\kappa$; PPV, positive predictive value. 
venous blood $\mathrm{Hb}$ according to its conversion into cyanmethaemoglobin ${ }^{(7)}$. Another method employed is the analysis of $\mathrm{Hb}$ by automated cell counters, which can use different reagents ${ }^{(8-10)}$. Both methods depend on venous blood collection, which is invasive, and are both costly and complex to operationalise. Epidemiological studies have used cheaper, less invasive and more practical methods for anaemia diagnosis, such as portable haemoglobinometers. This equipment analyses $\mathrm{Hb}$ based on azide methaemoglobin concentration and its immediate measurement can be performed with capillary blood samples ${ }^{(5,11,12)}$.

Studies assessing the reproducibility and reliability of portable haemoglobinometers in determining $\mathrm{Hb}$ concentrations and estimating anaemia prevalence have been carried out since the $1980 \mathrm{~s}^{(4,9,13-25)}$. However, considerable heterogeneity has been identified with regard to the age range of the group studied (i.e. children, adults), the type of blood sample analysed (venous or capillary blood), the standard method adopted (automated cell counters, cyanmethaemoglobin) and the performance assessment used (reliability). Eight studies included children ${ }^{(9,15,17,18,22-25)}$; among them, five assessed the performance of HemoCue ${ }^{\circledR}$ in determining $\mathrm{Hb}$ based on capillary blood samples compared with a standard method with venous blood samples ${ }^{(17,22-25)}$. None of them compared children below 2 years of age with the older ones.

Despite some studies suggesting good performance by the haemoglobinometers, it is important to consider that reliability and reproducibility are not inherent to a certain method: its performance is dependent on the study's context ${ }^{(26)}$. Two aspects that could differ among the settings and influence the method's performance are: the age range of the group studied (assuming that the method's performance depends on the calibre of the vessels from where the capillary blood samples are collected) and the prevalence/level of severity of the anaemia (assuming that the method's performance can be different depending on $\mathrm{Hb}$ level/distribution).

In settings where the prevalence of anaemia varied between 20 and $50 \%$ studies found good correlation between HemoCue ${ }^{\circledR}$ and the standard method ${ }^{(17,22)}$. On the other hand, in those with higher (above $65 \%)^{(25)}$ or lower (below $\left.15 \%\right)^{(24)}$ prevalence rates, the method's performance was worse.

The objective of the present study was to assess the reproducibility and reliability of a portable haemoglobinometer in diagnosing anaemia in children $<2$ and $\geq 2$ years, users of the public health system in Brazil's second largest city in a context of mild prevalence of anaemia $(13.7 \%)$, according to the $\mathrm{WHO}^{(27)}$. More information on reproducibility and reliability of portable haemoglobinometers in young children will contribute to the assessment of their performance in settings potentially different from those where previous studies with young children were carried out.

\section{Materials and methods}

\section{Public health problem definition}

Anaemia is defined as the condition in which the $\mathrm{Hb}$ content in the blood is below normal as a result of the lack of one or more essential nutrients such as $\mathrm{Fe}, \mathrm{Zn}$, vitamin $\mathrm{B}_{12}$ and protein. However, Fe-deficiency anaemia is much more common than the others. The prevalence of anaemia as a public health problem can be categorised: (a) no public health problem when prevalence of anaemia is $<5 \%$; (b) mild public health problem when prevalence of anaemia is $5-19.9 \%$; (c) moderate public health problem when prevalence of anaemia is 20 $39.9 \%$; and (d) severe public health problem when prevalence of anaemia is $\geq 40 \%{ }^{(3)}$.

\section{Study design, population and sample}

A cross-sectional study was carried out on a probabilistic sample of children aged 6-59 months, users of the Brazilian public health system (Sistema Único de Saúde; SUS) in the municipality of Rio de Janeiro who were enrolled in the 'Anemia and Vitamin A deficiency in preschool children: prevalence in a major urban centre and validation of diagnostic methods' survey.

Children were excluded from the study if they presented infectious diseases, such as pneumonia and otitis, among others, as well as sickle cell anaemia and hepatopathies. To calculate the sample size, the following parameters were considered: anaemia prevalence of $60.2 \%$, a value adopted based on a systematic review of studies carried out among health facilities $^{(5)}$; correlation values resulting from previous studies that evaluated $\mathrm{Hb}$ using portable haemoglobinometers ${ }^{(9,13,16)}$, with the most conservative being adopted; absolute study precision of 0.20 and $95 \%$ reliability level. By applying these parameters, a total of 111 children was reached. The sample size was calculated using the Stata v.10 program.

Considering that: (a) part of the correlation values adopted as a parameter for calculating the sample size was not obtained from studies with children, and (b) these parameters were attained treating the variables of interest in their continuous form, while in the present study variables were also analysed categorically, the sample size was increased by $50 \%$, totalling 167 children. Assuming $30 \%$ of refusals, at least 217 children should be invited to participate. Children were randomly selected maintaining the Sistema Único de Saúde (SUS) database 1.5 ratio between those over and under the age of 2 years.

The survey that originated this study included 536 children aged 6-59 months and revealed an anaemia prevalence of $13.7 \%$. The present study was carried out on a subsample of children who had $\mathrm{Hb}$ levels measured by both venous blood in an automated system and capillary blood in a portable haemoglobinometer ( $n$ 351; $158<2$ years and $193 \geq 2$ years).

This study was approved by the Rio de Janeiro Municipal Health Office Ethics Committee for Research with Humans (no. 203A/2013). Parents or legal guardians were duly informed about the risks and benefits of taking part in the study. The study was conducted only on children whose parents or guardians agreed to their participation and signed a free and informed consent form. Blood test results were returned by researchers directly to the guardians of the children studied on pre-scheduled dates. Children who presented any disorder were referred to the Health Unities where the study had been carried out. The survey was supported by the National 
Scientific and Technological Development Council (Conselho Nacional de Desenvolvimento Científico e Tecnológico (CNPq) 480804/2013-3) and by the municipality of Rio de Janeiro.

\section{Blood sample collection and Hb analysis}

Data collection was carried out between July and December 2014. Venous and capillary blood samples were collected by trained technicians experienced in collecting children's blood samples.

Standard method. We collected $4 \mathrm{~h}$ fasting venous blood samples into $0.5 \mathrm{ml}$ EDTA evacuated tubes. For children under 1 year old, the blood was collected with a syringe and immediately transferred into EDTA tubes. The tubes were transported to the clinical analysis laboratory in a cool box up to $4 \mathrm{~h}$ after collection for $\mathrm{Hb}$ analysis which was performed on the same day.

$\mathrm{Hb}$ concentration on venous blood samples was analysed by the automated XS1000i Sysmex ${ }^{\circledR}$ counter through the standard sodium lauryl sulfate (SLS)-Hb) detection method.

Test method. After venous blood collection, a capillary puncture of the middle or ring finger (children $\geq 1$ year) or heel (children $<1$ year) was performed using disposable lancets. Three samples of capillary blood were collected from each child. The first and second sample tests (sample test 1 and sample test 2) were collected from the same puncture for the analysis for $\mathrm{HemoCue}^{\circledR}$ reproducibility. The third sample test (sample test 3) was obtained from a second puncture performed on another finger or on another region of the heel in order to evaluate method reproducibility. According to the portable haemoglobinometer manufacturer recommendations, the first drop was discarded for each puncture.

$\mathrm{Hb}$ concentration in capillary blood samples was carried out by a portable HemoCue ${ }^{\circledR} \mathrm{Hb} 301$ model haemoglobinometer by the azide methaemoglobin detection method (test method) ${ }^{(13)}$.

\section{Data analysis}

To describe the group studied, the following variables were considered: age, sex, nutritional status (according to height-for-age and BMI-for-age), according to WHO classification criteria ${ }^{(28)}$ and maternal level of education. Nutritional status assessment was carried out using WHO Anthro Software ${ }^{(29)}$.

$\mathrm{Hb}$ concentration was considered the outcome variable, which was analysed in its continuous as well as categorical form (anaemic $v$. non anaemic). Children were considered anaemic if their $\mathrm{Hb}$ levels were below $11.0 \mathrm{~g} / \mathrm{dl}(6.8 \mathrm{mmol} /$ $1)^{(3)}$. The normality of the $\mathrm{Hb}$ distribution was confirmed through Kolgomorov-Smirnov.

To describe the outcome in the group studied, Hb distributions obtained by both methods were presented in graphs and central tendency (means and medians) and dispersion (standard deviations, variances and interquartile ranges) measures were estimated. The statistical program SPSS version 17.1 was used for data analysis.

\section{Reproducibility assessment of the measures}

The reproducibility of the HemoCue ${ }^{\circledR}$ device was assessed by checking the consistency of the measures between sample test 1 and sample test 2, obtained from the same puncture of the children's finger or heel. The reproducibility of the method was assessed by checking the consistency of the measures between sample test 1 and sample test 3 .

Assessment of reproducibility of both the device and method was performed using the intraclass correlation coefficient (ICC) to analyse the correlation between the results of the continuous variable ( $\mathrm{Hb}$ concentration), assuming that values above 0.70 indicate good correlation ${ }^{(30)}$. For the variable in its categorical form (anaemia yes/no), $\kappa$ coefficient and prevalence-adjusted bias-adjusted $\kappa(\mathrm{PABAK})^{(31)}$ were used, since the $\mathrm{K}$ coefficient is influenced both by the event prevalence and the measurement bias. The agreement values for $\kappa$ and PABAK were interpreted by the classification proposed by Byrt $^{(32)}:-1 \cdot 00$ to $0 \cdot 00$ : no agreement; $0 \cdot 01$ to $0 \cdot 20$ : poor; 0.21 to 0.40 : superficial; 0.41 to 0.60 : fair; 0.61 to $0 \cdot 80$ : good; 0.81 to 0.92 : very good; and 0.93 to 1.00 : excellent.

\section{Portable haemoglobinometer reliability assessment}

Assessment of the test method accuracy was carried out by comparing the mean $\mathrm{Hb}$ values and anaemia prevalence obtained from HemoCue ${ }^{\circledR}$ with those results obtained from the standard method. Comparisons between mean $\mathrm{Hb}$ values were conducted by paired Student's $t$ test and comparisons between prevalence ratios were conducted using the McNemar $\chi^{2}$ test, adopting a 0.05 significance level. The agreement between $\mathrm{Hb}$ values obtained by the standard and test methods was examined using Bland-Altman analyses.

Sensitivity, specificity, accuracy index, positive predictive value (PPV) and negative predictive value (NPV) of the test method were also calculated in order to evaluate the test method accuracy in the individual anaemia diagnosis ${ }^{(30,33)}$.

\section{Results}

\section{Population characteristics}

Among the 351 children who took part in the study, 51.0\% were females and $45 \%$ were aged between 6 and 23 months. The mean age was 16.0 (SD) 5.0 months for children $<2$ years and 41.6 (SD 10.5) for those $\geq 2$ years. Concerning the maternal level of education, $52.1 \%$ had completed elementary school, $44.0 \%$ had concluded high school education and $3.9 \%$, higher education. These results were similar for both age groups studied. With regard to the nutritional status, $4.9 \%$ had low height for age, $23 \%$ were at risk of overweight, $5.6 \%$ were overweight and $2.5 \%$ were obese (BMI/age). The prevalence of anaemia was $19.1 \%$ for the total group, being 32.9 and $7.8 \%$ for children $<2$ and $\geq 2$ years, respectively. 


\section{Device and method reproducibility}

The distributions of $\mathrm{Hb}$ values were similar between the three test method samples for both the total group studied and by age range (Fig. 1).

According to the ICC, the agreement observed between sample tests 1 and 2 was good (varying between 0.75 and $0 \cdot 81$ ), and a little higher than that observed between sample tests 1 and 3 (which varied between 0.68 and 0.71 ) (Table 1). When analysing $\mathrm{Hb}$ as a categorical variable, agreement was fair between sample test 1 and sample test $2(\kappa=$ $0 \cdot 43)$ and superficial between test 1 and test $3(\kappa=0 \cdot 36)$ for the total group, with better results observed for children $<2$ years ( $\kappa=0.46$ and 0.42 , respectively) compared with those observed for older children ( $\kappa=0 \cdot 28$ and $0 \cdot 18$, respectively). When using PABAK, agreement was good (varying between 0.61 and 0.69 ), except for sample tests 1 and 2 among children $<2$ years, which remained fair $(0 \cdot 54)$ (Table 1$)$.

\section{Reliability of the portable haemoglobinometer}

The distribution of $\mathrm{Hb}$ values obtained by standard and test methods resulted in considerably overlapped curves, with values slightly higher for the test method for both the total group (Fig. 2(a)) and by age range (Fig. 2(b) and 2(c)).

For the total group, $\mathrm{Hb}$ mean values obtained through the standard method and the test method (respectively, 11.86 and $12.04 \mathrm{~g} / \mathrm{dl}(7.36$ and $7.47 \mathrm{mmol} / \mathrm{l}))$ showed a statistically significant difference $(P<0 \cdot 001)$, although the magnitude of that difference was not very large $(0.18 \mathrm{~g} / \mathrm{dl}(0.11 \mathrm{mmol} / \mathrm{l}))$ (Table 2). A similar result was observed for both age groups. A Bland-Altman plot shows that the mean difference between $\mathrm{Hb}$ values estimated by the test and standard methods was $-0.17 \mathrm{~g} / \mathrm{dl}(-0.11 \mathrm{mmol} / \mathrm{l})$, with $95 \%$ limits of agreement from -1.98 to $1.62 \mathrm{~g} / \mathrm{dl}(-1.23$ to $1.01 \mathrm{mmol} / \mathrm{l})$ (Fig. 3).

No statistically significant differences were observed for the anaemia prevalence obtained by both the standard and test methods for the total group (19.1 and $19.7 \%$, respectively), children $<2$ years (32.9 and $29.1 \%$, respectively) and older children ( 7.8 and $11.9 \%$, respectively) (Table 2 ).

Regarding the performance of the test method in the individual diagnosis of anaemia, it was observed that for the total group studied as well as for children in each age group $(<2$ and $\geq 2$ years), it showed higher specificity $(87 \cdot 7,76 \cdot 7$ and $95.9 \%$, respectively) than sensitivity $(50 \cdot 7,56.5$ and $34.8 \%$, respectively), suggesting more accuracy in false positive exclusion. The test method also showed higher NPV (88.3, 81.1 and $91.6 \%$, respectively) than PPV (49.3, 50.0 and $53.3 \%$, respectively). The accuracy index was $57.8 \%$ for the total group studied, with quite distinct results within each age range $(73.6$ and $36 \%$ for $<2$ and $\geq 2$ years, respectively) (Table 3).

\section{Discussion}

The test method showed good reproducibility when considering $\mathrm{Hb}$ as a continuous variable and fair reproducibility for $\mathrm{Hb}$ in its categorical form. When compared with the standard (a)

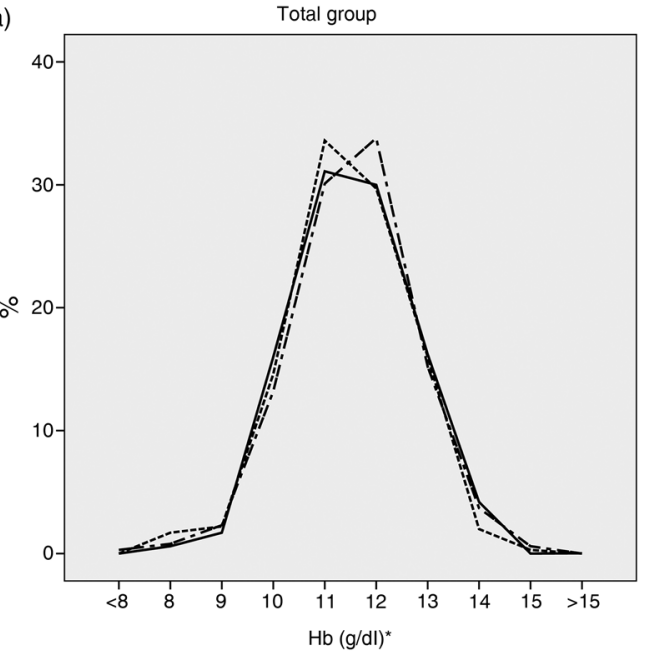

(b)

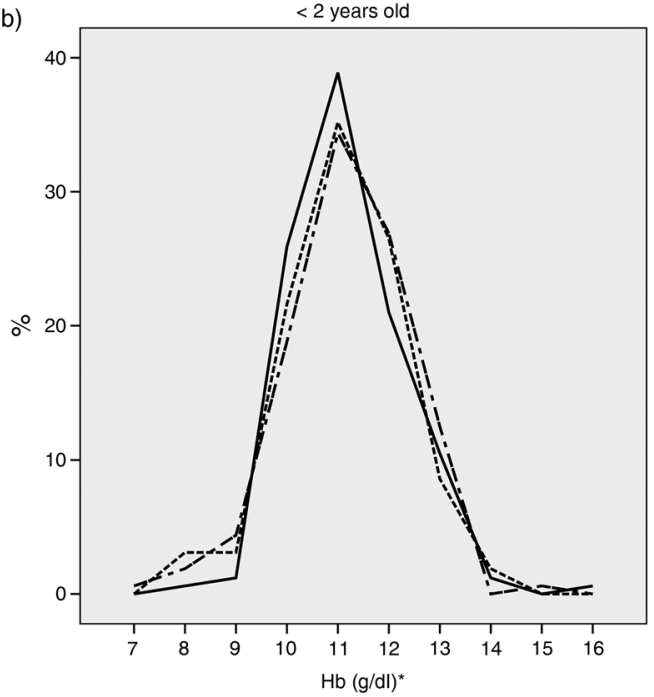

(c)

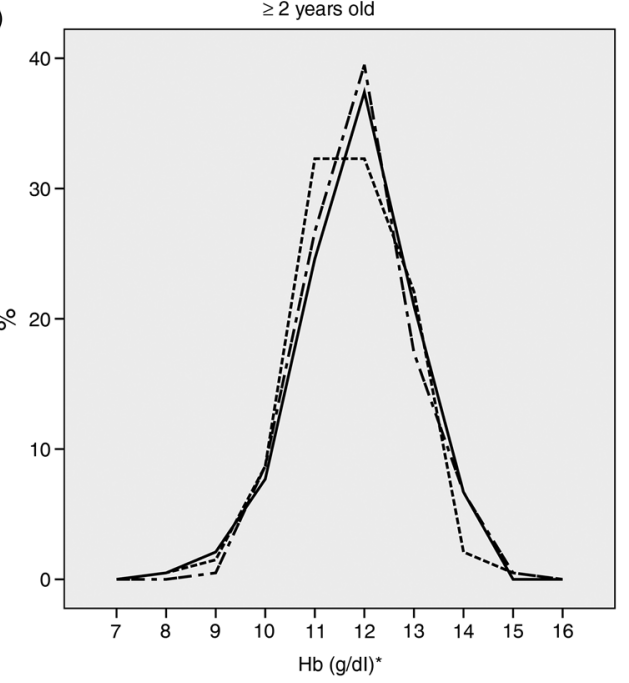

Fig. 1. Distribution of $\mathrm{Hb}$ concentration of three capillary blood samples obtained through a portable haemoglobinometer in children aged 6 to 59 months (Rio de Janeiro, 2014). $n 357$ (sample test 1 (-) v. sample test 2 $(-))$ and $n 355$ (sample test $1 \mathrm{v}$. sample test $3(--)$ ). Sample test 1: first drop of capillary blood, extracted from the first puncture, read on a portable haemoglobinometer. Sample test 2: second drop of capillary blood, extracted from the first puncture, read on a portable haemoglobinometer. Sample test 3: third drop of capillary blood, extracted from the second puncture, read on a portable haemoglobinometer. (a) Total group; (b) < 2 years old; (c) $\geq 2$ years old. * To convert $\mathrm{Hb}$ in $\mathrm{g} / \mathrm{dl}$ to $\mathrm{mmol} / \mathrm{l}$, multiply by 0.6206 . 
Table 1. $\mathrm{Hb}$ concentration, intraclass correlation coefficient, $\kappa$ and adjusted $\kappa$ for $\mathrm{Hb}$ determination and diagnosis of anaemia by portable haemoglobinometer in children aged 6 to 59 months by age group (Rio de Janeiro, 2014)*

\begin{tabular}{|c|c|c|c|c|c|}
\hline \multirow[b]{2}{*}{ Test method } & \multicolumn{2}{|c|}{$\mathrm{Hb}(\mathrm{g} / \mathrm{dl}) \dagger$} & \multirow{2}{*}{$\begin{array}{l}\text { Intraclass } \\
\text { correlation } \\
\text { coefficient }\end{array}$} & \multirow[b]{2}{*}{$\kappa$} & \multirow[b]{2}{*}{ Adjusted $\mathrm{\kappa}$} \\
\hline & Mean & SD & & & \\
\hline \multicolumn{6}{|l|}{ Children $<2$ years } \\
\hline Sample test $1 \neq$ & 11.70 & 1.06 & - & - & - \\
\hline Sample test $2 \S$ & 11.57 & $1 \cdot 16$ & 0.81 & 0.46 & 0.54 \\
\hline Sample test 3\| & 11.67 & $1 \cdot 15$ & 0.68 & 0.42 & 0.61 \\
\hline \multicolumn{6}{|l|}{ Children $\geq 2$ years } \\
\hline Sample test 1 & $12 \cdot 31$ & 1.08 & & & \\
\hline Sample test 2 & $12 \cdot 18$ & 1.06 & 0.75 & 0.28 & 0.69 \\
\hline Sample test 3 & $12 \cdot 28$ & 0.98 & 0.68 & 0.18 & 0.67 \\
\hline \multicolumn{6}{|l|}{ Total } \\
\hline Sample test 1 & 12.04 & 1.11 & - & - & - \\
\hline Sample test 2 & $11 \cdot 70$ & $1 \cdot 15$ & 0.79 & 0.43 & 0.62 \\
\hline Sample test 3 & 12.00 & $1 \cdot 10$ & 0.71 & 0.36 & 0.63 \\
\hline
\end{tabular}

${ }^{*} n 357$ (test 1 v. test 2) and 355 (tests 1 v. 3). Test method: Hb concentration in capillary blood sample analysed by portable haemoglobinometer (HemoCue ${ }^{\circledR} \mathrm{Hb} 301$ ). † To convert $\mathrm{Hb}$ in $\mathrm{g} / \mathrm{dl}$ to $\mathrm{mmol} / \mathrm{l}$, multiply by 0.6206 .

‡ Sample test 1: 1st drop of capillary blood, extracted from the first puncture, read on a portable haemoglobinometer.

$\S$ Sample test 2: 2nd drop of capillary blood, extracted from the first puncture, read on a portable haemoglobinometer.

\| Sample test 3: 3rd drop of capillary blood, extracted from the second puncture, read on a portable haemoglobinometer.

method, it showed higher $\mathrm{Hb}$ averages, similar anaemia prevalence estimates, low PPV and sensitivity, high NPV and specificity and intermediate accuracy index.

The comparison of these results with those from other publications is limited given the difference, among the studies, in the age range of the group analysed, the type of blood samples used (resulting from capillary and/or venous blood), the standard method used (cyanmethaemoglobin or azide methaemoglobin) and the statistical tests used. Nevertheless, it can be observed that other studies also verified higher $\mathrm{Hb}$ concentration in capillary blood analysed by portable haemoglobinometer when compared with that measured in a venous blood sample. In a study carried out from 2000 to 2002 with 413 children from Kansas and 213 from St Louis, USA, with ages varying from 12 to 35 months, Boghani et al. ${ }^{(24)}$ observed higher $\mathrm{Hb}$ concentrations in capillary blood analysed using HemoCue ${ }^{\circledR}(12.5$ and $11.6 \mathrm{~g} / \mathrm{dl}(7 \cdot 8$ and $7.2 \mathrm{mmol} / \mathrm{l}$ ), respectively) when compared with those obtained from venous blood analysed by the automated system $(11.8$ and $11.5 \mathrm{~g} / \mathrm{dl}(7.3$ and $7.1 \mathrm{mmol} / \mathrm{l})$, respectively), with no statistically significant difference.

A converging result was obtained in a study conducted in India with 100 children aged 1-6 years which compared capillary blood $\mathrm{Hb}$ concentrations analysed by HemoCue ${ }^{\circledR}$ with venous blood analysed by the cyanmethhaemoglobin method. In that study, a larger $(1.19 \mathrm{~g} / \mathrm{dl}(0.7 \mathrm{mmol} / \mathrm{l}))$ and statistically significant difference in between methods was observed $^{(18)}$.

On the other hand, Levy et al. ${ }^{(23)}$ performed a study with 137 children aged 1-5 years in San Luis Potosí, Mexico, in 2015, and found a lower mean capillary blood $\mathrm{Hb}$ level $\left(12.7 \mathrm{~g} / \mathrm{dl}(7.9 \mathrm{mmol} / \mathrm{l})\right.$, analysed using HemoCue $\left.{ }^{\circledR}\right)$ when compared with that obtained from venous blood $(14.2 \mathrm{~g} / \mathrm{dl}$
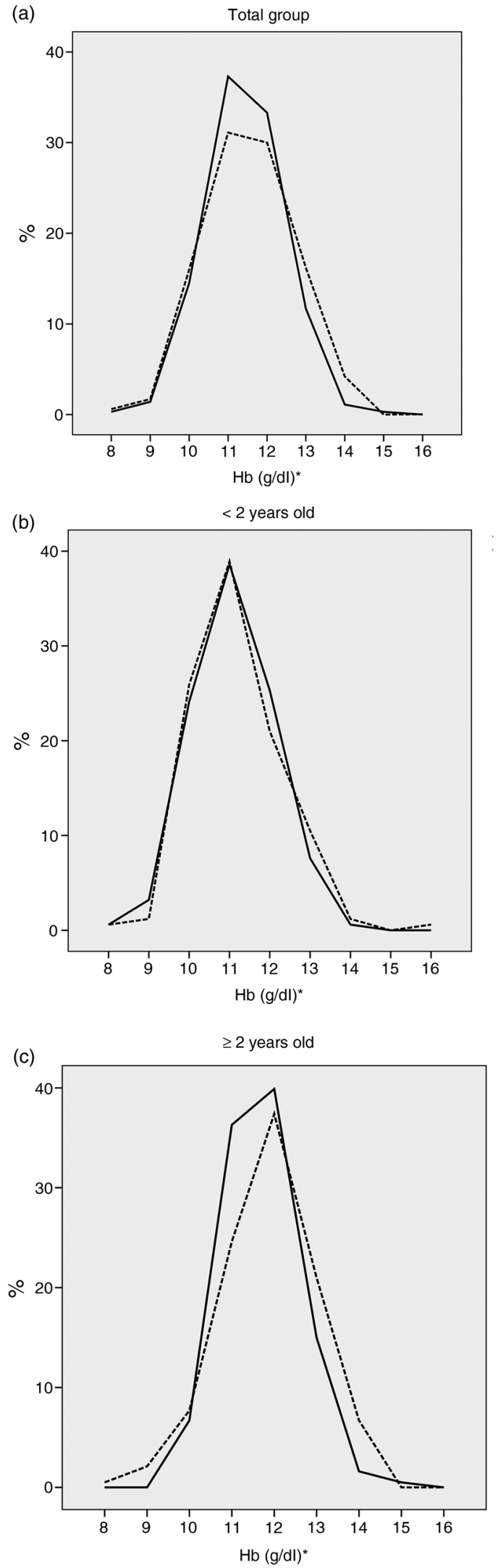

Fig. 2. Distribution of $\mathrm{Hb}$ concentration according to the standard method (-) and the test method (--) carried out on children aged 6 to 59 months by age group (Rio de Janeiro, 2014). $n$ 351. Standard method: Hb analysis in venous blood samples by automated system (XS1000i Sysmex ${ }^{\circledR}$ ). Test method: $\mathrm{Hb}$ concentration in capillary blood sample analysed by portable haemoglobinometer (HemoCue ${ }^{\circledR} \mathrm{Hb}$ 301). (a) Total group; (b) $<2$ years old; (c) $\geq 2$ years old. * To convert $\mathrm{Hb}$ in $\mathrm{g} / \mathrm{dl}$ to $\mathrm{mmol} / \mathrm{l}$, multiply by 0.6206 . 
Table 2. Hb concentration and prevalence of anaemia according to the standard method and the test method in children aged 6 to 59 months $(n 351)$ by age group (Rio de Janeiro, 2014)

\begin{tabular}{|c|c|c|c|c|c|c|}
\hline \multirow[b]{2}{*}{ Method } & \multicolumn{5}{|c|}{$\mathrm{Hb}(\mathrm{g} / \mathrm{dl})^{*}$} & \multirow[b]{2}{*}{ Prevalence of anaemia (\%) } \\
\hline & Mean & SD & Median & Variance & Interquartile range & \\
\hline \multicolumn{7}{|c|}{ Children $<2$ years } \\
\hline Standard $†$ & 11.52 & 0.99 & 11.50 & 1.00 & 1.40 & $32.9 \neq$ \\
\hline Test§ & 11.70 & $1.06 \|$ & 11.70 & 1.13 & 1.40 & $29 \cdot 1 \ddagger$ \\
\hline \multicolumn{7}{|c|}{ Children $\geq 2$ years } \\
\hline Standard $\dagger$ & $12 \cdot 14$ & 0.87 & $12 \cdot 10$ & 0.75 & 1.20 & $7 \cdot 8 \ddagger$ \\
\hline Test§ & $12 \cdot 31$ & $1.08 \|$ & 12.40 & $1 \cdot 18$ & 1.60 & $11.9 \ddagger$ \\
\hline \multicolumn{7}{|l|}{ Total } \\
\hline Standard $\dagger$ & 11.86 & 0.97 & 11.80 & 0.95 & 1.30 & $19 \cdot 1 \ddagger$ \\
\hline Test§ & $12 \cdot 04$ & $1.11 \|$ & $12 \cdot 00$ & 1.25 & 1.50 & $19 \cdot 7 \ddagger$ \\
\hline
\end{tabular}

* To convert $\mathrm{Hb}$ in $\mathrm{g} / \mathrm{dl}$ to $\mathrm{mmol} / \mathrm{l}$, multiply by 0.6206

† Standard method: $\mathrm{Hb}$ concentration in venous blood sample analysed by automated system (XS1000i Sysmex ${ }^{\circledR}$ ).

$\ddagger$ No statistically signficant difference $(P>0.05)$ between prevalences of anaemia obtained by the standard method and the test method (McNemar's $\chi^{2}$ test).

$\S$ Test method: $\mathrm{Hb}$ concentration in capillary blood sample analysed by portable haemoglobinometer (HemoCue $\left.{ }^{\circledR} \mathrm{Hb} 301\right)$.

\| Statistically significant difference $(P<0.05)$ between the mean $\mathrm{Hb}$ concentration obtained by the standard method and the test method (Student's $t$ test for paired samples).

$(8 \cdot 8 \mathrm{mmol} / \mathrm{l}))$ analysed by the automated system, with a statistically significant difference.

Studies using $\mathrm{HemoCue}^{\circledR}$ to assess $\mathrm{Hb}$ concentration from a venous blood sample showed higher concentrations when compared with the blood samples analysed by an automated system or by cyanmethaemoglobin ${ }^{(15,22)}$. On the other hand, in a study carried out in Morelos, Mexico, with seventy-two children aged 6 months- 15 years a higher $\mathrm{Hb}$ concentration was observed by the automated system both with capillary and venous blood samples, when compared with HemoCue ${ }^{\circledR(17)}$.

The difference between $\mathrm{Hb}$ concentration in venous and capillary blood is shown in other studies and is biologically plausible ${ }^{(21,34-36)}$. Patel $e t$ al. ${ }^{(21)}$ suggest that the contents of a drop of capillary finger blood reflect the blood contents of different finger capillaries, which can alter the determination of $\mathrm{Hb}$ concentration. Furthermore, the authors suggest that the capillary blood sample from the finger depends on skin thickness and temperature, the depth of the lancet penetration and the finger blood extraction technique performed by the professional. Furthermore, Hagan et al. ${ }^{(37)}$ emphasise the importance of body positioning at the time of collection, since this may influence the $\mathrm{Hb}$ values in capillary blood; blood samples collected in the supine position produce higher results than those obtained in a vertical position.

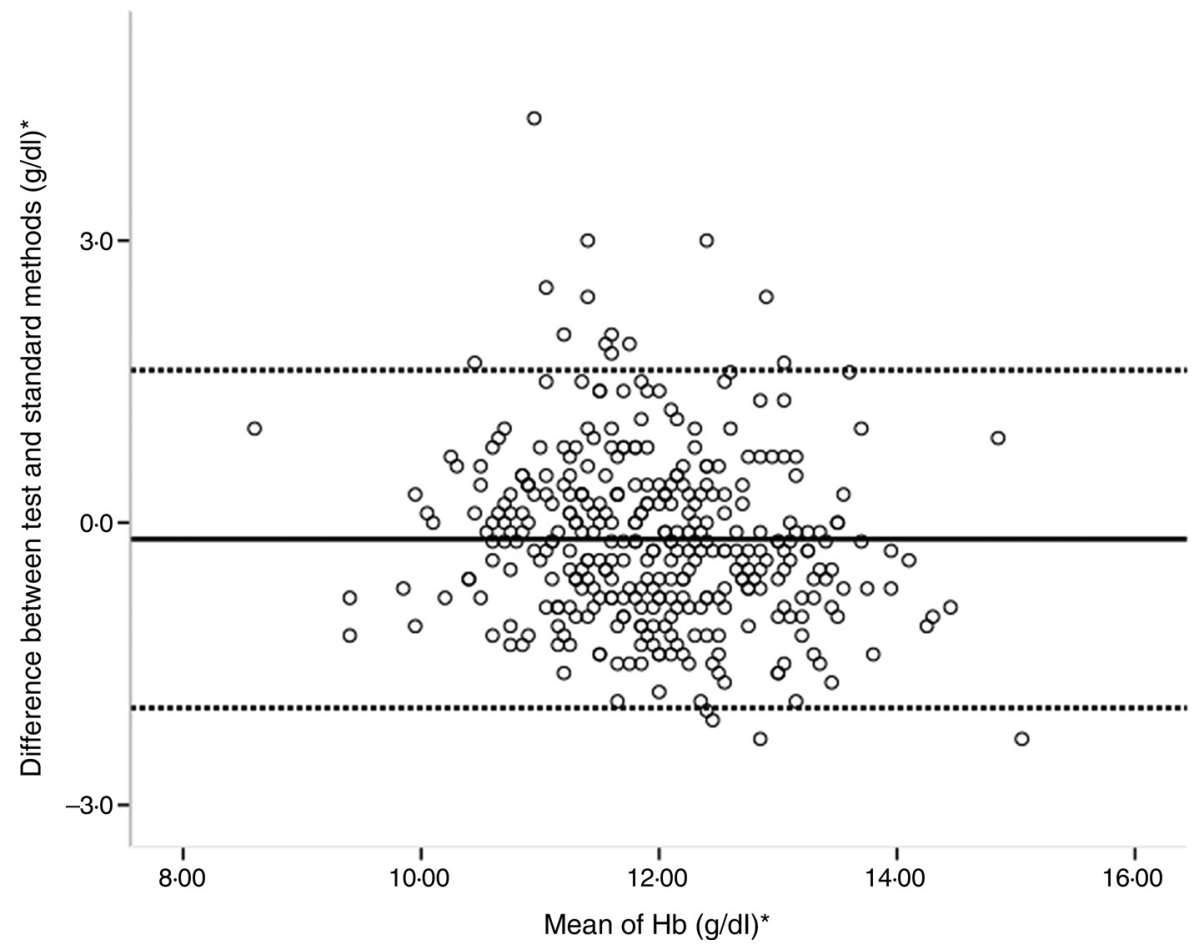

Fig. 3. Bland-Altman plot showing agreement in $\mathrm{Hb}$ concentration of children aged 6 to 59 months of Rio de Janeiro assessed by test method ( $\mathrm{Hb}$ concentration in capillary blood sample analysed by portable haemoglobinometer: HemoCue $\left.{ }^{\circledR} \mathrm{Hb} 301\right)$ and standard method $(\mathrm{Hb}$ analysis in venous blood samples by automated system: XS1000i Sysmex ${ }^{\circledR}$ ). * To convert $\mathrm{Hb}$ in $\mathrm{g} / \mathrm{dl}$ to $\mathrm{mmol} / \mathrm{l}$, multiply by 0.6206 . 
Table 3. Sensitivity, specificity, accuracy index, positive predictive value and negative predictive value of the portable haemoglobinometer compared with the automated system for estimating anaemia in children aged 6 to 59 months according to age group (Rio de Janeiro, 2014)

\begin{tabular}{lccccc}
\hline Age group & Sensitivity (\%) & Specificity (\%) & Accuracy index (\%) & Positive predictive value (\%) & Negative predictive value (\%) \\
\hline Children $<2$ years $(n$ 158) & 56.5 & 76.7 & 73.6 & 50.0 & 81.1 \\
Children $\geq 2$ years $(n 193)$ & 34.8 & 95.9 & 36.3 & 53.3 & 91.6 \\
Total $(n$ 351) & 50.7 & 87.7 & 57.8 & 49.3 & 88.3 \\
\hline
\end{tabular}

In the present study, ICC values indicated good consistency for the portable haemoglobinometer (ICC above $0 \cdot 70$ ) in determining $\mathrm{Hb}$ concentrations with the same capillary puncture (comparison between sample tests 1 and 2) both for the total group and by age range. For capillary blood samples resulting from another puncture (comparison between sample tests 1 and 3), ICC values were very close to $0 \cdot 70$, suggesting good reproducibility for HemoCue ${ }^{\circledR}$. In a study involving eightyseven females, Morris et al. ${ }^{(15)}$ observed reasonable haemoglobinometer reproducibility for determining $\mathrm{Hb}$ in capillary blood samples at different sites (left and right hand fingers; ICC = 0.69), and fair reproducibility in capillary blood samples from the same person on 4 consecutive days (ICC $=0 \cdot 50$ ). Paiva et $a l^{(38)}$, on the other hand, observed fair reproducibility (ICC $=0 \cdot 60$ ) of HemoCue ${ }^{\circledR}$ in determining $\mathrm{Hb}$ in the capillary and venous blood samples of twenty-nine pregnant women.

On a complementary basis, the CV of the results ${ }^{(39)}$ was also examined. CV values were relatively high, especially among children $<2$ years $(10.2 \%$ for test 2 and $9.8 \%$ for test 3 ), when compared with those from other studies with children. In the study conducted by Morris et al. ${ }^{(15)}$ with eighty-seven woman from Honduras and seventy-three from Central Bangladesh, the $\mathrm{CV}$ in determining $\mathrm{Hb}$ from two different sites (one in each hand, study from Honduras) in the same day was $6.3 \%$ and in 4 consecutive days (study from Bangladesh) was $7 \cdot 0 \%$. In a study conducted with twenty-nine children with ages ranging from 15 to 32 months, in Khammouane province, Laos, in 2016, Hinnouho et al. ${ }^{(25)}$ compared the venous blood $\mathrm{Hb}$ values obtained by three different portable haemoglobinometer devices and observed CV values ranging from 6.1 to 8.0 among them. Paiva et al. ${ }^{(38)}$, in a study with twenty-nine pregnant women, observed the $\mathrm{CV}$ for the determination of $\mathrm{Hb}$ values analysed by the haemoglobinometer with capillary blood $(\mathrm{CV}=13 \cdot 6)$ and venous blood samples $(\mathrm{CV}=17)$. Von Schenck et al. ${ }^{(13)}$ observed good precision from HemoCue ${ }^{\circledR}(\mathrm{CV}=1.3 \%)$ in determining $\mathrm{Hb}$ when they analysed fifty-two pairs of capillary blood samples from young adults of both sexes.

In the haemoglobinometer reproducibility analysis for $\mathrm{Hb}$ in its categorical form, $\kappa$ values showed that the haemoglobinometer showed better performance in capillary blood samples from the same puncture (sample tests 1 and 2) when compared with samples from the second puncture (sample tests 1 and 3), in both age groups, showing better results among the younger children. PABAK values indicated the influence of prevalence in the present findings. Calculating the contribution of the bias component within this dataset, it was observed that it did not influence the PABAK result. By comparing both age groups, it was possible to observe that among the children under 2 years of age, who presented higher anaemia prevalence, the difference observed between the $\kappa$ and PABAK values was smaller. These results reiterate the assertion that reproducibility is not a characteristic inherent to the method, and reinforce the importance of evaluating the performance of the haemoglobinometer in different scenarios. We did not find in studies that $\kappa$ and/or PABAK was used to analyse the reproducibility of the portable haemoglobinometer, which limited the comparison of our results with the literature.

Regarding the reliability, in this study the haemoglobinometer presented superficial reliability and showed better performance in detecting the individual situation of absence of anaemia. Converging results to this were registered by Boghani et al. ${ }^{(24)}$, who observed sensitivity of 32.8 and 60.4 $\%$ and specificity of 97.7 and $85.6 \%$ between the children from Kansas and those from St Louis, respectively. Hinnouho et al. ${ }^{(25)}$ evaluated the reliability of the portable haemoglobinometer for the determination of anaemia comparing capillary and venous blood samples, from 1487 Laotian children, analysed by an automated system and observed a sensitivity of $68.7 \%$ and specificity of $85.8 \%$.

It is worth mentioning that both studies mentioned showed a similar design to that in the present study; in other words, comparison of the portable haemoglobinometer in determining anaemia based on $\mathrm{Hb}$ concentration in capillary blood samples with that obtained from a venous blood sample and analysed by an automated system as standard method.

Other studies, however, have shown a better ability of the haemoglobinometer to detect true anaemics. It is worth highlighting, however, that in these cases the participants' age group and the blood sample analysed by the test method (venous blood) were different from those adopted here. In a study carried out with 184 children aged from 72 to 102 months using venous blood samples both in the test and standard methods, Gwetu \& Chhagan ${ }^{(22)}$ assessed the ability of the HemoCue $^{\circledR}$ device to detect anaemia and observed sensitivity of $93 \%$ and specificity of $74.5 \%$. In the study conducted by Boghani et al. ${ }^{(24)}$, the authors also evaluated the haemoglobinometer performance with venous blood samples in a group of children from Kansas and observed sensitivity of $51.7 \%$, higher, therefore, than that obtained from capillary blood samples $(32.8 \%)$. In a study with 320 individuals aged 18-63 years attending a blood donation centre, Shahshahani et al. ${ }^{(40)}$ evaluated the method's sensitivity and specificity on individuals with a high mean $\mathrm{Hb}(\geq 18 \mathrm{~g} / \mathrm{dl}(\geq 11.2 \mathrm{mmol} / \mathrm{l}))$ and low mean $\mathrm{Hb}(<12.5 \mathrm{~g} / \mathrm{dl}(<7.8 \mathrm{mmol} / \mathrm{l}))$ and observed, in the first group, sensitivity and specificity of 96.3 and $85.7 \%$ for venous blood samples and 100 and $79.8 \%$ for capillary 
blood samples, both analysed by portable haemoglobinometer. The authors observed that in the group with lower $\mathrm{Hb}$ levels, sensitivity dropped and specificity rose for both types of blood samples analysed.

In the present study, among the children $<2$ years, the group in which a higher prevalence of anaemia was observed (32.9 $\%$, we found low sensitivity, low PPV and high NPV values. The opposite was found in children $\geq 2$ years, who showed low anaemia prevalence $(7.8 \%)$. In the study conducted by Neufeld et al. ${ }^{(17)}$, in which a prevalence of $41.9 \%$ of anaemia was found among infants and adolescents aged 6 months to 15 years, and in which HemoCue ${ }^{\circledR}$ performance was assessed through capillary blood samples, the following values were found: sensitivity $84 \%$, specificity $93 \%$, PPV $90 \%$ and NPV $89 \%$. As previously reported, Shahshahani et al. ${ }^{(40)}$ found that among adult blood donors, in the group showing lower capillary blood $\mathrm{Hb}$ concentration, HemoCue ${ }^{\circledR}$ was less sensitive than specific, when compared with the one with higher $\mathrm{Hb}$ concentrations.

In a study carried out with 500 platelet donors in which a prevalence of $5.8 \%$ of anaemia was found, Malhi et al. ${ }^{(41)}$ found a sensitivity of $50 \%$ using HemoCue ${ }^{\circledR}$ in the detection of anaemia using capillary blood samples when compared with venous blood samples analysed by an automated system, while specificity was $98.5 \%$. PPV and NPV were 70.8 and $96.4 \%$, respectively.

A strength of our study was the number of children studied, which allowed investigating the test method performance in children under 24 months and between 24 and 59 months of age. HemoCue ${ }^{\circledR}$ showed greater stability in children $<2$ years. Lower $\mathrm{Hb}$ concentration, expected in younger children, could be one of the reasons for this finding. Knowing the performance of the portable haemoglobinometer on children under the age of 5 years in a context where anaemia prevalence was lower than those generally found in similar studies also contributed towards the innovative character of the present study.

Another strength of the study was the use of the $\kappa$ and PABAK measurements, as well as ICC, to evaluate the reproducibility of HemoCue ${ }^{\circledR}$, suggesting that it is important to assess HemoCue's ${ }^{\circledR}$ reproducibility not only regarding the determination of $\mathrm{Hb}$ concentration, but also in relation to the detection (diagnosis) of the problem to be studied. The use of PABAK enabled knowing the influence of the prevalence of the event of interest in the $\kappa$ index. A third positive aspect of the study was the analysis of the portable haemoglobinometer's reliability for diagnosing anaemia as well as for estimating the prevalence of this disease. In other words, we provided data on its performance for both individual and collective diagnosis, differing from many of the studies cited, which frequently did not present any prevalence data.

A weak point of the study to be mentioned is the fact that no analyses of the portable haemoglobinometer were carried out with venous blood samples, which would allow for the ascertainment of the haemoglobinometer's differences in determining $\mathrm{Hb}$ in both blood sample types. The decision to analyse only capillary blood samples was due to the fact that, in practice, HemoCue ${ }^{\circledR}$ is used in epidemiological studies with such type of samples.

\section{Conclusion}

HemoCue ${ }^{\circledR}$ showed good device reproducibility and reasonable method reproducibility, as well as good performance in estimating the prevalence of anaemia. Nevertheless, it showed a fair reliability and low individual diagnostic accuracy, especially in the group of children $\geq 2$ years, which presented low anaemia prevalence. Therefore, the utilisation of HemoCue ${ }^{\circledR}$ appears to be adequate in population-based studies aimed at estimating the prevalence of anaemia among children, but not for the purpose of individual diagnosis, especially in contexts with low anaemia prevalence.

\section{Acknowledgements}

The authors are grateful to all families that participated of the study and all researchers that participated in the data collection.

The survey was supported by the National Scientific and Technological Development Council (Conselho Nacional de Desenvolvimento Científico e Tecnológico (CNPq) 480804/ 2013-3) and by the municipality of Rio de Janeiro.

A. da S. P. contributed to the study design, participated in data collection and in the construction of the database, performed the analysis of the data, conducted the manuscript writing and revised the final version of the manuscript to be published. I. R. R. de C. contributed to the study design, supervised the analysis of the data, participated in the writing of the manuscript and revised the final version of the manuscript to be published. F. F. B. contributed to the study design, collaborated in the blood sample analysis and revised the final version of the manuscript to be published. J. F. N. N. contributed to the study design and coordinated the blood sample analysis. A. C. F. da S. supervised the analysis of the data, participated in the writing of the manuscript and revised the final version of the manuscript to be published.

There are no conflicts of interest.

\section{References}

1. Lozof B (2007) Iron deficiency and child development. Food Nutr Bull 28, S560-S571.

2. Soliman AT, Sanctis V \& Sanjay K (2014) Anemia and growth. Indian J Endocrinol Metab 18, S1-S5.

3. World Health Organization (2015) The Global Prevalence of Anaemia in 2011. Geneva: World Health Organization.

4. Rosenblit J, Abreu CR, Szterling LN, et al. (1999) Evaluation of three methods for hemoglobin measurement in a blood donor setting. Rev Paul Med 117, 108-112.

5. Vieira RCS \& Ferreira HS (2010) Prevalência de anemia em crianças brasileiras, segundo diferentes cenários epidemiológicos (Prevalence of anaemia in Brazilian children according to different epidemiological scenarios). Rev Nutr Campinas 23, 433-444.

6. Srivastava T, Negandhi H, Neogi SB, et al. (2014) Methods for hemoglobin estimation: a review of 'what works'. Hematol Transfus 2, 1028.

7. International Council for Standardisation in Haematology (ICSH) (1996) Recommendations for reference method for haemoglobinometry in human blood (ICSH standard 1995) and specifications for international haemiglobincyanide standard. Clin Patbol 49, 271-274.

8. Azim W, Parveen S \& Parveen S (2002) Comparison of photometric cyanmethemoglobin and automated methods for hemoglobin estimation. J Ayub Med Coll Abbottabad 14, 22-23. 
9. Nkrumah B, Nguah SB, Sarpong N, et al. (2011) Hemoglobin estimation by the HemoCue ${ }^{\circledR}$ portable hemoglobin photometer in a resource poor setting. BMC Clin Pathol 11, 5.

10. Chakravarthy VK, Chandra DN, Prasanna BS, et al. (2012) Haemoglobin estimation by non-cyanide methods. J Clin Diagn Res 6, 955-958.

11. Matta IEA, Veiga GV, Baião MR, et al. (2005) Anemia em crianças menores de cinco anos que freqüentam creches públicas do município do Rio de Janeiro, Brasil (Anaemia in children under five who attend public day care centres in the city of Rio de Janeiro, Brazil). Rev Bras Saúde Matern Infant 5, 349-357.

12. Guled RA, Mamat NB, Balachew T, et al. (2017) Predictors and prevalence of anemia, among children aged 6 to 59 months in Shebelle zone, Somali region, eastern Ethiopia: a cross sectional study. Int J Dev Res 7, 11196.

13. Von Schenck H, Falkenuon M \& Lundberg B (1986) Evaluation of 'HemoCue,' a new device for determining hemoglobin. Clin Chem 32, 526-529.

14. Cohen AR \& Seidl-Friedman J (1988) Hemocue ${ }^{\circledR}$ system for hemoglobin measurement. Evaluation in anemic and nonanemic children. Am J Clin Pathol 90, 302-305.

15. Morris SS, Ruel MT, Cohen RJ, et al. (1999) Precision, accuracy, and reliability of hemoglobin assessment with use of capillary blood. $A m$ J Clin Nutr 69, 1243-1248.

16. Sari M, Pee S, Martini E, et al. (2001) Estimating the prevalence of anaemia: a comparison of three methods. Bull World Health Organ 79, 506-511.

17. Neufeld L, García-Guerra A, Sánchez-Francia D, et al. (2002) Hemoglobin measured by Hemocue and a reference method in venous and capillary blood: a validation study. Salúd Pública Mex 44, 219-227.

18. Bhaskaram P, Balakrishna N, Radhakrishna KV, et al. (2003) Validation of hemoglobin estimation using Hemocue. Indian J Pediatr 70, 25-28.

19. Cable RG, Steele WR, Melmed RS, et al. (2012). The difference between fingerstick and venous hemoglobin and hematocrit varies by sex and iron stores. Transfusion 52, 1031-1040.

20. Shah N, Osea EA \& Martinez GJ (2014) Accuracy of noninvasive hemoglobin and invasive point-of-care hemoglobin testing compared with a laboratory analyzer. Int J Lab Hematol 36, 56-61.

21. Patel AJ, Wesley R, Leitman SF, et al. (2013) Capillary versus venous hemoglobin determination in the assessment of healthy blood donors. Vox Sang 104, 317-323.

22. Gwetu TP \& Chhagan MK (2015) Evaluation of the diagnostic accuracy of the HemoCue device for detecting anaemia in healthy school aged children in KwaZulu-Natal, South Africa. S Afr Med J 105, 596-599.

23. Levy TS, Méndez-Gómez-Humarán I, Ruán MCM, et al. (2017) Validation of Masimo Pronto 7 and HemoCue 201 for hemoglobin determination in children from 1 to 5 years of age. PLOS ONE 12, e0170990.
24. Boghani S, Mei Z, Perry GS, et al. (2017). Accuracy of capillary hemoglobin measurements for the detection of Anemia among U.S. low-income toddlers and pregnant women. Nutrients 9, E253.

25. Hinnouho GM, Barffour M, Wessells KR, et al. (2018) Comparison of haemoglobin assessments by HemoCue ${ }^{\circledR}$ and two automated haematology analysers in young Laotian children. J Clin Pathol 71, 532-538.

26. Keszei AP, Novak M \& Streiner DL (2010) Introduction to health measurement scales. J Psychosom Res 68, 319-323.

27. World Health Organization (2001) Arcbived: Iron Deficiency Anaemia: Assessment, Prevention and Control: a Guide for Programme Managers. Geneva: World Health Organization.

28. World Health Organization (2006) Child Growth Standards. Geneva: World Health Organization.

29. World Health Organization (2011) WHO Anthro Software, version 3.2.2. Geneva: World Health Organization. https://www.who.int/ childgrowth/software/anthro_pc_manual_v322.pdf?ua=1 (accessed December 2019).

30. Streiner DL, Norman GR \& Cairney J (2015) Health Measurement Scales - a Practical Guide to Their Development and Use. Oxford, UK: Oxford University Press.

31. Byrt T, Bishop J \& Carlin JB (1993) Bias, prevalence, and к. J Clin Epidemiol 46, 423-429.

32. Byrt T (1996) How good is that agreement? Epidemiology 7, 561.

33. Kawamura T (2002) Interpretação de um teste sob a visão epidemiológica. Eficiência de um teste (Interpretation of a test from the epidemiological view. Efficiency of a test). Arq Bras Cardiol 79, 437-441.

34. Radtke H, Polat G, Kalus U, et al. (2005) Hemoglobin screening in prospective blood donors: comparison of different blood samples and different quantitative methods. Transfus Apher Sci 33, 31-35.

35. Daves M, Cemin R, Zagler EM, et al. (2016) Evaluation of capillary haemoglobin determination for anaemia screening in blood donation settings. Blood Transfus 14, 387-390.

36. Mohan G, Bhaskaran R, Sudha SP, et al. (2016) Comparison of pre donation hemoglobin screening methods - implications of quality and cost. Int J Contemp Med Res 3, 2064-2067.

37. Hagan RD, Diaz FJ \& Horvath SM (1978) Plasma volume changes with movement to supine and standing positions. J Appl Physiol 45, 414-417.

38. Paiva AA, Rondóa PHC, Silva SSB, et al. (2004) Comparison between the $\mathrm{HemoCue}^{\circledR}$ and an automated counter for measuring hemoglobin. Rev Saúde Pública 38, 585-587.

39. Schottenfeld J \& Fraumeni F (2006) Cancer Epidemiology and Prevention. Oxford, UK: Oxford University Press.

40. Shahshahani HJ, Mera at N \& Mansouri F (2013) Evaluation of the validity of a rapid method for measuring high and low haemoglobin levels in whole blood donors. Blood Transfus 11, 385-390.

41. Malhi SCRS, Pawar MA, Kushwaha MN, et al. (2016) Point of care hemoglobin testing in platelet pheresis donors: noninvasive versus invasive methods. Med J Armed Forces India 72, 338-343. 